Cinemas in Santiago. Artifacts of modernity in urban transformation

PALABRAS CLAVE • CIUDAD · SALAS CINEMATOGRÁFICAS TIPOLOGÍA EVOLUCIÓN, ESTILOS

KEYWORDS • CITY · CINEMAS · TYPOLOGY · EVOLUTION ·

\title{
Los cines en Santiago
}

\section{Artefactos de modernidad en la transformación urbana*}

\author{
MARCELO VIZCAÍNO · Universidad Andrés Bello, Santiago, Chile · marcelovizcaino@gmail.com \\ CLAUDIO GARRIDO · Universidad Diego Portales, Santiago, Chile · claudio_garrido_p@yahoo.com \\ CLAUDIA BOSSAY · Universidad de Chile, Santiago, Chile · claudiabossay@gmail.com \\ Fecha recepción: 12 de septiembre 2020 · Fecha aceptación: 14 de noviembre 2020
}

\section{INTRODUCCION}

Al concluir la primera mitad del siglo $X X$, el proceso de adaptación, localización y construcción de cines en Santiago reveló una red espacial de lugares de proyección, que acompañó a la expansión planificada de la ciudad. Dichos ámbitos de exhibición resultaron con formas genéricas originadas en otros lugares que posibilitaron el surgimiento de nuevos hábitos entre los ciudadanos. Este artículo hace foco en tipos de salas de cine para reflexionar acerca del impacto social y constructivo que se inició con los "cine-coliseo" y hasta integró el programa complejo de edificios de inversión. El conjunto de casos fue un detonante cultural en la capital del país y sirven para explorar su rol en la consolidación de la modernidad, a nivel de la vivencia que ofrecían el consumo de las películas y su correlato material de la arquitectura con la ciudad.

\section{ABSTRACT}

At the end of the first half of the twentieth century, the process of adapting, localizing, and constructing cinemas in Santiago revealed a spatial network of projection sites that developed alongside with the planned expansion of the city. These exhibition spaces, resulted in generic forms that originated in other places, that allowed the emergence of new habits among citizens. This article focuses on types of cinemas as a way to reflect the social and constructive impact that began with the cinemascolosseum, and that comprise the complex program of buildings for investment. This set of cases was a cultural trigger in the capital of the country, and it helped to explore its role in the consolidation of modernity, at the level of experience offered by the consumption of films and its material correlation of architecture with the city.
El cine, entendido tanto en su producción material constructiva como en la producción de experiencias de exhibición de filmes durante la primera mitad del siglo XX, se presenta en su desarrollo como un "artefacto cultural" (Revert, 2012, p. 5). Un edificio resultante de una emergencia explosiva que gesta hábitos regulares en los espectadores, y a la vez, modifica la geografía urbana de Santiago, introduciendo nuevos desafíos en la arquitectura, en un período en que se precipitaban diversos cambios en la ciudad.

Este fenómeno social es resultado de un negocio floreciente que acompaña una ciudad en crisis y que requería un nuevo orden para su transformación espacial debido a la gran cantidad de migrantes que llegaban del campo a la urbe (Vyhmeister-Fábregas, 2019). En la primera década del siglo XX, Santiago alberga constantes cambios que modifican tanto a la arquitectura como a la experiencia de la ciudad. De esta manera, se consolida la movilidad urbana e interurbana fortaleciendo el proceso de modernización metropolitana, instrumentado con políticas urbanas que impactan multiplicando la oferta de servicios, especialmente aquellos dedicados al ocio.
El cine, conocido popularmente en sus primeras décadas como biógrafo, lo conforman un amplio conjunto de máquinas (Kinorascope, Kinetoscopio, Eidoloscope, Bioscopio, y Cinematógrafo) que proyectan imágenes en movimiento. Los inventos se instalan en una caseta sobre elevada y ventilada, lo que permite un enfoque correcto para encuadrar y proyectar en una pared ciega y alejada, o bien, sobre una tela tensada. Estas son condiciones necesarias y básicas que cumplen tanto para recintos tipo pabellón como los teatros existentes, y que se acomodan para ofrecer este flamante entretenimiento.

Un eficaz mecanismo comercial de la exhibición de películas se fortalece en las áreas distantes del centro de Santiago. Allí, en los barrios populares donde cualquier recinto que cumpla con las mínimas condiciones podía convertirse en un lugar referencial de entretención. Así, este conjunto de espacios para proyección de variedades impulsa una actividad que sobrepasa al teatro como espacio público de masas, estableciéndose como un fenómeno eminentemente urbano y moderno (Rosas, Hidalgo, Strabucchi y Cordano, 2010, p. 71). Teatros adaptados -como los del centro-y barracones -como proliferan en la periferiaestablecen una mediación entre las dimensiones 
públicas y privadas, a través de un conjunto de prácticas establecidas y en función de la concurrencia al visionado de una historia filmada.

Para 1910, se suman doce locales: Apolo, Brasil, Ideal, Victoria, Politeama, Zigzag (Figura 1), San Diego, Sucesos, Andacollo, Independencia, París y Alameda; a los ya existentes, Variedades, Kinora, Parisiana, Arturo Prat, Circo Nacional y Royal Saloon. Esto demuestra que el centro histórico santiaguino se convierte en un laboratorio espacial de edificios que, como ensayos formales, despliegan un proceso de levantar edificios para proyectar películas, promoviendo otros hábitos sociales.

La metodología de la investigación de origina este artículo comienza con el levantamiento cronológico de los cines que funcionan en Santiago entre los años 1922 y 1960. De este estudio se determinan dos categorías: espacios adaptados y nuevos edificios que se levantan para proyectar. En ambas se recabó la información cultural que tal actividad genera en su contexto. Con estos datos, luego se traza el despliegue del espectáculo cinematográfico santiaguino y en cuya distribución temporal, de dichas salas, se detecta un acompañamiento singular de los cines con el Plan Urbano que transformaba a la ciudad. Así, se comprueba que los cines se constituyeron en agentes de la cultura urbana de principios del siglo XX.

Del catastro confeccionado, y de manera paradojal, se revela que la aparición de los iniciales edificios para el cine se originan en la periferia santiaguina o mejor dicho, en predios alejados del centro; en cambio, sucede en el centro de Santiago donde estas obras logran su plenitud. En estos dispares contextos, ciertas costumbres sociales asociadas al cine promueven inéditas y homólogas nuevas formas de vivir, experimentando distintos sectores de la ciudad.

No obstante de reconocer particularidades tipológicas en la arquitectura de los edificios

1. Fachada e interior del Teatro ZIG-ZAG. (Fuente: Revista Zig Zag, 22 enero 1910).

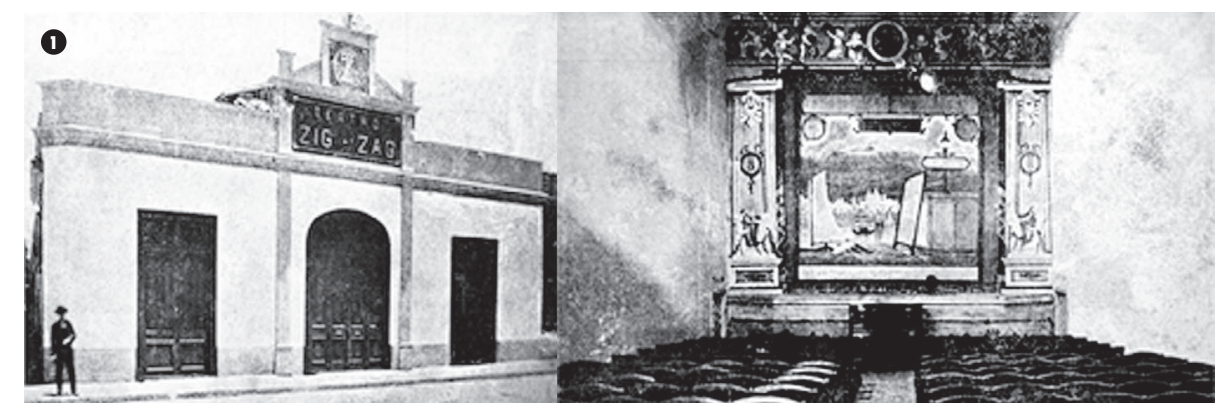

levantados especialmente para el cine, el propósito de abordar esta temática se plantea a nivel panorámico. El presente texto se enfoca en analizar y describir como la apertura y funcionamiento de salas detonan focos urbanos que irrumpieron el paisaje urbano, modificaron las costumbres citadinas y evolucionaron como artefactos al servicio de las películas y de la flamante industria cultural. Así, los cines se identifican como piezas funcionales a la modernización de Santiago.

\section{EL CINE Y LA CIUDAD}

Como se menciona, el imaginario dominante que fue tomando el cine se lo vincula estrechamente a los sectores populares y no a la élite. De alguna manera, esto muestra otra faz del correlato de los cambios que germinaron un Plan Urbano para transformar a la capital. Santiago ya no era una ciudad incipiente, con una sociedad dominada únicamente por la élite; se trataba, por el contrario, de una ciudad en plena expansión, donde se expresaba la sociedad de masas (Romero, 1976). Con esto, vale aclarar que hasta los inicios de los años 20, entre todas las listas de salas revisadas en los medios especializados, se comprueba que dos tercios de ellas estaban ubicadas en barrios populares. Sin embargo, esta circunstancia cambia cuando se institucionalizan los reglamentos de espacios para proyectar, su fiscalización y el reconocimiento de exhibición de peliculas como negocio privado. La entrada de Chile al modelo de consumo de cine internacional y el arribo de leyes de propiedad privada de las películas, repercuten en la necesidad de crear espacios pensados en torno a la audiencia y la generación de una oferta diferenciadora por parte de cada sala.

El negocio de la exhibición cinematográfica surge de una formula esencial en donde un alto número de vecinos permitía la apertura de las salas y por ende, un público asegurado para una proyección libre y sin restricciones de propiedad. Durante la década 1920, el área de mayor concentración de habitantes continua siendo el centro histórico de la ciudad, mientras los sectores emergentes (Recoleta, Quinta Normal y barrio el Llano) elevan sus cifras de población casi hasta equipararlo. En el centro, la transformación moderna se pone en evidencia con edificios del Estado que buscan generar la materialidad y el tránsito propio de una república moderna regida por valores cívicos (Arizaga, 2019), cuestión que se expresó con el estudio y la aprobación del Plan de Karl Brunner; a la vez que en la periferia, lo populoso y el desarrollo cada vez más creciente de estos barrios, auspician la presencia de una alta venta de butacas. Cabe plantear que ambos aspectos, modernidad y audiencia, constituyen factores que propician una arquitectura nueva, "propia del cine" donde se logra aumentar los estándares de calidad y consolidar la práctica de la ciudadanía de ver películas. De este modo se crean nuevos espacios en donde enmarcar y vincular este "habitus" (Bourdieau en Martínez García, 2017, p. 35) forjado de la experiencia y sociabilidad vinculada al cine. 
El habitus instala y valida la dimensión del entretenimiento, la expectación y la concurrencia colectiva como formas de construir un renovado perfil del santiaguino; éste se vincula a las recientes tonalidades de significados que se distinguen a los lugares tradicionales con los edificios modernos pujantes, contraste con que comienza a identificar al centro histórico. Aun así, la población más interesada en ir al cine vive en la periferia y por eso, hay que atraerlos hasta el centro, ofreciendo espacios acordes a estos cambios que reconfiguran una ciudad moderna.

\section{LOS TEMPLOS DEL ENTRETENIMIENTO POPULAR}

En 1922 se inaugura el teatro ${ }^{[1]}$ Esmeralda, cuya capacidad para más de dos mil espectadores, le otorga la distinción de primer cine del país diseñado para proyectar películas. El edificio se ubica en el cruce de calles San Diego con Aconcagua y el proyecto es realizado por Monckeberg y Aracena. Desde lo social, es clave entender por qué que este gran cineteatro se reconoce como trascendental para la ciudad, "el teatro más hermoso después del Municipal" (Diario El llustrado, 31 de marzo de 1922 , p. 27) que curiosamente, no se levanta en el centro, sino en un lugar urbano altamente poblado y transitado. Desde lo espacial, el gran volumen de la sala no resalta en la elevación de la calle, sino que retrocede hacia el interior de la manzana, por ende, no aporta una llamativa fachada, como mostraban las revistas de cine y arquitectura a los cines extranjeros, sino que se destacan los locales comerciales sobre la vereda (Figura 2).

Se puede especular que para lograr la captación de un público masivo, la elección del lugar
2. Cines Esmeralda y O'Higgins. Las vitrinas comerciales eran protagónicas hacia la calle, replegando el volumen de la sala hacia el interior de la manzana. (Fuentes: Diario La Tercera - Autor).

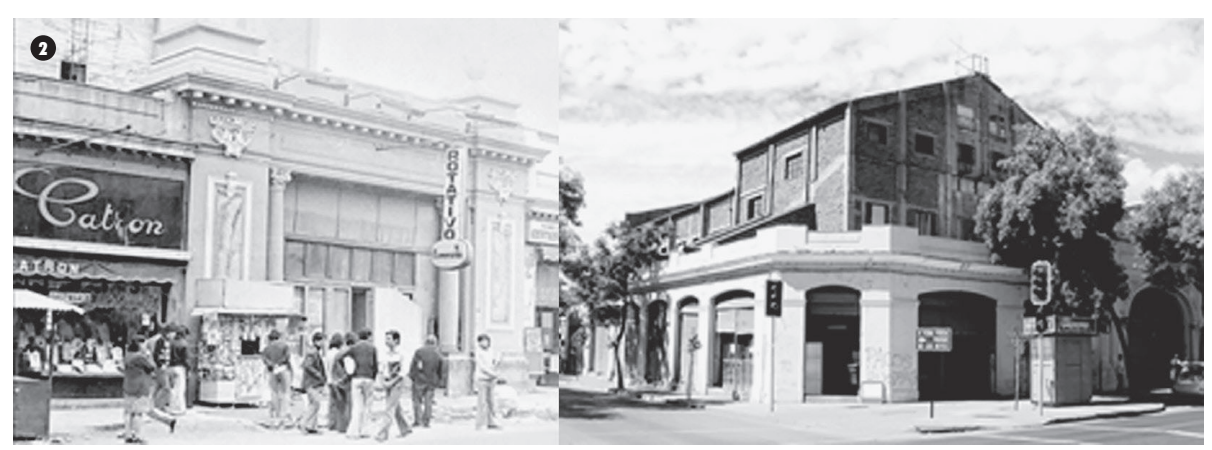

donde construir la sala depende, no solo de elegir un terreno óptimo en un sector populoso, sino también brindar más comodidades en comparación a los espacios de proyección existentes, hecho que necesariamente no se traduce en lujos arquitectónicos. A pesar de esto, el Esmeralda es un edificio clave que "consolidó el proceso de modernización de las salas" (Purcell, 2012, p. 43) que se construyeron posteriormente, consolidando una modalidad de negocio: cine con locales comerciales, constituyendo una tipología arquitectónica hasta entonces atípica: una "hibridación programática" (Vizcaíno, 2020, p. 18). El programa de ver películas constituye una fase entre otras que se amarra y conforma el paseo de compras con entretenimiento. De modo que la magia de la sala a oscuras crea expectativa en un habitual recorrido previo, o bien, en el acostumbrado debate de la caminata, una vez que concluye la función.

Terminado los años 20, cuando la llegada del cine sonoro volvía indispensable más acondicionamientos de las salas, la revista Crítica anticipa que "los cines de barrios se extinguirían". Seguramente se presume que ésta sería la verdadera revolución en el negocio de la cinematografía, desaparecería toda esa formidable maraña de competencias chiquitas, para irse de frente a la gran competencia de las capitales y de las excelencias definitivas de los regios locales ${ }^{[2]}$. En esta cita, se hace evidente la considerable cantidad de cines de barrio que constituyen una dinámica red urbana, donde el entretenimiento opera junto a otros programas públicos (comercio, plazas, iglesias) y, por ende, el rol de la arquitectura es determinante para delinear las nuevas salas de cine. Así, se decantan las necesidades por renovar sus espacios interiores (equipos de proyección, butacas, decoración), las fachadas y considerar además la higiene y seguridad (baños, sistema contra incendios, salidas de emergencias, etc.) como se consigna en las reglamentaciones vigentes.

En la transformación del centro de la capital, el dilema que afecta a las proyecciones cinematográficas es levantar los "edificios para cine" como parte de la institucionalización planificada. Es decir, que las empresas cinematográficas deben construir espacios para ver mejor las películas, superar a la tipología del teatro italiano ${ }^{[3]}$ y acoger los avances

[1] En Chile, durante largo tiempo los cines siguieron llamándose teatros, posiblemente debido a la diferencia social que denotaba asistir a los primeros en comparación a la popularidad de los biógrafos; también puede deberse a que, en los comienzos de la actividad cinematográfica, los biógrafos se instalaron dentro de los teatros. Así, el uso indistinto de cine y teatro perduró hasta los primeros años del siglo XXI.

[2] Revista Crítica, Santiago, 15 julio de 1929.

[3] El formato de referencia alude al espacio de la representación teatral compuesto por un volumen cerrado y con un escenario elevado que concita la mirada de los espectadores en un único plano de visión. 
tecnológicos que imponía la proyección. Para esto, un gesto evidente es la "monumentalidad" promovida por los propios empresarios de la industria de las salas de cine, que no solo fortalece la próspera industria de exhibición cinematográfica, sino que aporta a la imagen de modernidad con la que paulatinamente se renueva Santiago.

Los formatos de salas de cine, difundidos por publicaciones de la época, apuntan a cambiar las calles con un perfil de más altura, lo que acusa el tamaño de la sala, además, un novedoso despliegue de iluminación en las marquesinas y también porque aledaños a éstas, se instalan café, restaurant y negocios para prolongar los lugares de encuentro. Esta tipología arquitectónica proyectada exclusivamente para el cine, es divulgada y reconocida popularmente como templos, coliseos (lturriaga, 2018) o palacios ${ }^{[4]}$ (AlfaroOchoa, 2019) los que estimularon distintos lenguajes decorativos para atraer espectadores, y a lo cual es imprescindible recalcar las proporciones de los casos en Santiago, ya que estos cines ofrecían una gran capacidad pero con cierta austeridad de la decoración, por lo cual ciertos autores adhieren a la denominación de coliseo (lturriaga, 2018, p 188).

Aun así, la arquitectura propone formas novedosas animando a ir al cine, moldeando el habitus, que consistía en una "experiencia mítica, fuera de lo común: el cine era el lugar de lo extraordinario, y la decoración de fachadas y foyers debía acompañar tal estado de ánimo" (García y Méndez, 2010, p. 23). Los cines que se levantan con distintos lenguajes arquitectónicos e incorporan a las artes decorativas para enmarcar una experiencia de elegancia y sofisticación. De este modo, el cine se nos presenta como paradigma tangible de cambios sociales, convirtiendo a la sala en un testimonio material que absorbe los ritmos y tendencias del contexto sociocultural (LavillaIrribarren, 2016, p. 70).

Tanto la arquitectura como los procesos urbanos que modifican a Santiago y a otras ciudades latinoamericanas, en las décadas iniciales del siglo XX, consideran a los cines como una pieza ejemplar de modernidad, ya que "de todas las construcciones que se edifican en nuestros días, la sala de cine es la que debe presentar el carácter más moderno"[5]. Por ejemplo, la incorporación del sonido en las películas constituye un factor determinante para la construcción de las salas de cine, lo que supone la introducción de inéditas claves, en las que los habitantes de Santiago acceden a una novedosa "sensación de modernidad" (Ávila, Montaño, 2015, p. 16). En este entendido, el cine se considera más naturalmente como una ventana en la que se asoma y descubre lo foráneo, con la expectación previa a sentarse frente a la pantalla, y aconteciendo todo esto en un nuevo espacio: un edificio particularmente concebido para brindar comodidad al espectador, adhiriendo y desplegando los avances tecnológicos de una mejor proyección.

\section{EL LUGAR PARA LOS CINES}

En el número 6-7 de la Revista Arquitectura y Artes Decorativas (1929), una nota sobre el Teatro Nacional abre elocuente: "el cine responde a la aplicación de un sistema acústico perfeccionado (Sala Pleyel)" y luego se explaya minuciosamente sobre el sistema de referencia, La nota aclara que se trata de un teatro popular con gran capacidad y que se realizó dentro de una estricta economía". Es interesante comprobar que el único párrafo dedicado a la arquitectura tiene una rotunda declaración sobre el lugar donde se construyó: "el sector de nuestra ciudad donde se alza este Teatro ha adquirido una significativa nota de progreso actual". Este coliseo, como un promotor de modernidad, se distingue por el imponente tamaño en un barrio no céntrico de Santiago.

La siguiente sala de cine que aparece en esta revista fue el Teatro Real, en el número 2 (1931), y a diferencia del ejemplo anterior, se presenta al edificio en trece páginas. Con un surtido material de fotografías y planos, se incluyó un texto que resulta curioso desde su inicio, en donde se parafrasea a Le Corbusier con un enunciado: "el teatro es una máquina de recrear". Es decir, que en esta ocasión, la crítica especializada alaba la idea del cine como artefacto de la ilusión implantado en el centro histórico y que tiene a la decoración como primer valor arquitectónico. Se plantea una contradicción inicial, ya que se resalta: "nunca nos hubiéramos podido imaginar que con la adopción del estilo renacimiento español-que tan poco adecuado nos figuraba para el ambiente de un cine moderno- se hubiesen podido obtener los efectos de elegancia y liviandad que se lograron aquí". Lo planteado aquí es que lo antagónico a moderno pareciera manifestarse mediante el "efecto" más precisamente que en la "apariencia" y sobretodo, al destacar la sorpresa de un estilo, posteriormente se desvía la declaración: no se inaugura un edificio con estándares contemporáneos, sino una arquitectura con fines artísticos y comerciales (sic). En este sentido parece que la modernidad solicitada, proyectada y construida se condensa solo en sus inéditas características: un gran vacío sin palcos, todas las ubicaciones frente al telón, sin apoyos intermedios para los espectadores, sistemas de ventilación y calefacción, construcción asísmica e incombustible.

Con estas notas antagónicas se revelan las características que asume el lugar elegido para levantar dos cines en la ciudad. En el primero, cuya presencia figura como "transferida de un catálogo" e implantado en sectores populares,
[4] Con respecto al concepto de cine-palacio (Valentine, 1994) proviene de los lujosos teatros construidos entre 1910 y 1940 en Estados Unidos. Estos se caracterizaban por albergar una gran cantidad de personas y tener elaboradas decoraciones y se divulgaron por el mundo a través de diversas publicaciones. Incluso, fueron renombrados en alusión como palacios-plebeyos en Buenos Aires (Cozarinsky, 2006).

[5] En el texto de Mallet-Stevens Les cinemas, catálogo de la exposición "L’Art dans cinemas" (París, 1924). 
llevando una visión de crecimiento y modernidad urbana, aun así, con la importante fachada art déco, casi totalmente desprovista de decoración, concitando especialmente la atención por su gran marquesina, la sala que no tuvo resonancia ${ }^{[6]}$ en la conformación posterior de edificios próximos en la avenida Independencia. En cambio, para el segundo caso, donde se aprueba al eclecticismo decorativo por sobre la modernidad (esencial del cine), el lugar elegido se valora y forja al edificio como atracción para instalar, cercano a este, cafés, restaurantes, librerías y de esta manera, detonar actividades previas o posteriores a la función (FIGURA 3).

Aunque la tipología funcional de estos ejemplos replica la misma secuencia ${ }^{[7]}$ de espacios (Alfaro, Ochoa, 2019, p. 8) el panorama formal del conjunto de cines inaugurados entre los años 30 y 60, y con el cual se fue desplegando la expansión de Santiago, se diferencia a partir del lugar donde se levantaban los edificios. En el centro, prevalece cierta ostentación decorativa, mientras que los en la periferia, resulta característica por la sensatez volumétrica que resultaban con una apariencia modesta (FIgURA 4).

\section{SALAS DEL CENTRO Y "LA CALLE DE LOS CINES"}

Como se dijo, cada cine del centro se divisa y reconoce en el paisaje urbano por una ornamentación distintiva. En el imaginario, el cine significaba adentrarse en lo exótico, lejano, legendario. La experiencia mítica del cine comenzaba antes de ver la película, el cine era el lugar de lo extraordinario, y la decoración de fachadas y foyers debían acompañar ese estado de ánimo (García, Méndez, 2010, p. 23). Por
3. Fachadas de los teatros Nacional y Real publicadas en Revista de Arquitectura y Artes Decorativas. (Fuente: Memoria chilena).

4. Contrastes estilísticos entre sala una del centro (Metro ubicada en calle Bandera) y otra de la periferia (cine Palace Ovalle). (Fuente: 92 cines).
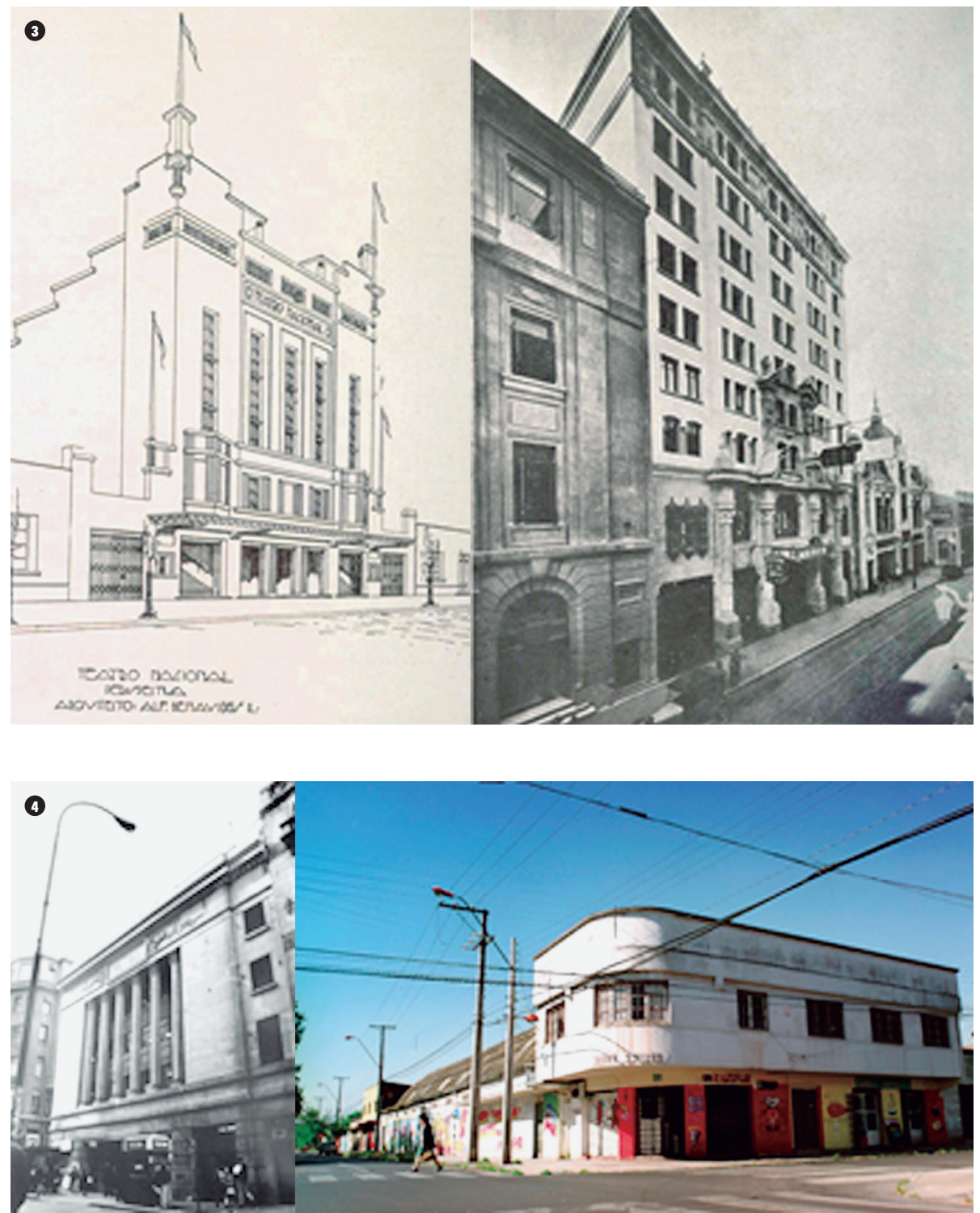

[6] Esto se verifica con una fotografía del año 1996, publicada en 92 Cines en que la sala se destaca por el volumen, ya que no tiene edificios colindantes acorde a su tamaño. El Teatro Nacional se mantuvo en pie como pabellón de ventas de una empresa maderera hasta el 2004, cuando fue demolida.

[7] Dado en el orden de: alero como transición entre la calle y el vestíbulo, boletería, vestíbulo principal, vestíbulo alto o foyer, sala principal, galería, servicios sanitarios por género (y ocasionalmente por nivel) y las circulaciones y salidas de emergencia directas a vía publica. 
esto, se puede reconocer el neo-colonial y toda su decoración interior que imita al cielo una noche estrellada (Real, 1930) ${ }^{[8]}$, el racionalistafuncional con evidente despojo de detalles (Santiago, 1935), ecléctico, denotado por la columnata de la fachada, llamativo remate de la cornisa y que en su interior desplegaba pinturas con motivos mexicanos (Metro, 1936) o beuxiartiano (Santa Lucía, 1937).

Estos primeros edificios para el cine se ubican dispersos en el centro y por eso, las proyecciones programadas modifican la permanencia de los transeúntes en este sector de la ciudad, con un horario ampliado y variada cartelera. Ir al cine se asentó en un acto social de modo "popular" (bastaba con vestirse acorde y pagar una entrada). En los templos se reconocen a los edificios construidos "de y para el cine". La asociación con el concepto de palacio es porque la nueva arquitectura se distinguía por el gran tamaño (para acoger una numerosa audiencia), inusuales y hasta disímiles rasgos estilísticos, con la marquesina que enmarcaba el frontis y anunciaba la película de turno.

Sin duda, cambian los hábitos que suceden en las calles santiaguinas. El centro adquiere una nueva alternativa al habitual tránsito funcional, mayoritariamente extendido hacia la racionalidad del trámite administrativo o el trabajo, agregando la posibilidad de vivirlo desde el tiempo libre y el "panorama del ocio". En este deambular es que aparece otra manera de permanecer para sus eventuales habitantes. El cine trae nuevos dispositivos visuales, tales como marquesinas, carteleras y afiches que dan otros colores al centro y a la experiencia de recorrer sus calles.

[8] Uno de los lujos de los cine-palacio era la noción de ser cines atmosféricos, ambos conceptos fueron acuñados por John Eberson. Estos sugerían estar bajo cielos estrellados o en lugares exóticos, como en villas italianas o españolas, en India, Persia o China. Dichas salas norteamericanas solían tener alrededor de 4.000 butacas.
5. Axonometría de la calle Huérfanos y despiece de salas. (Fuente: Dibujo de Brayan Valdés).

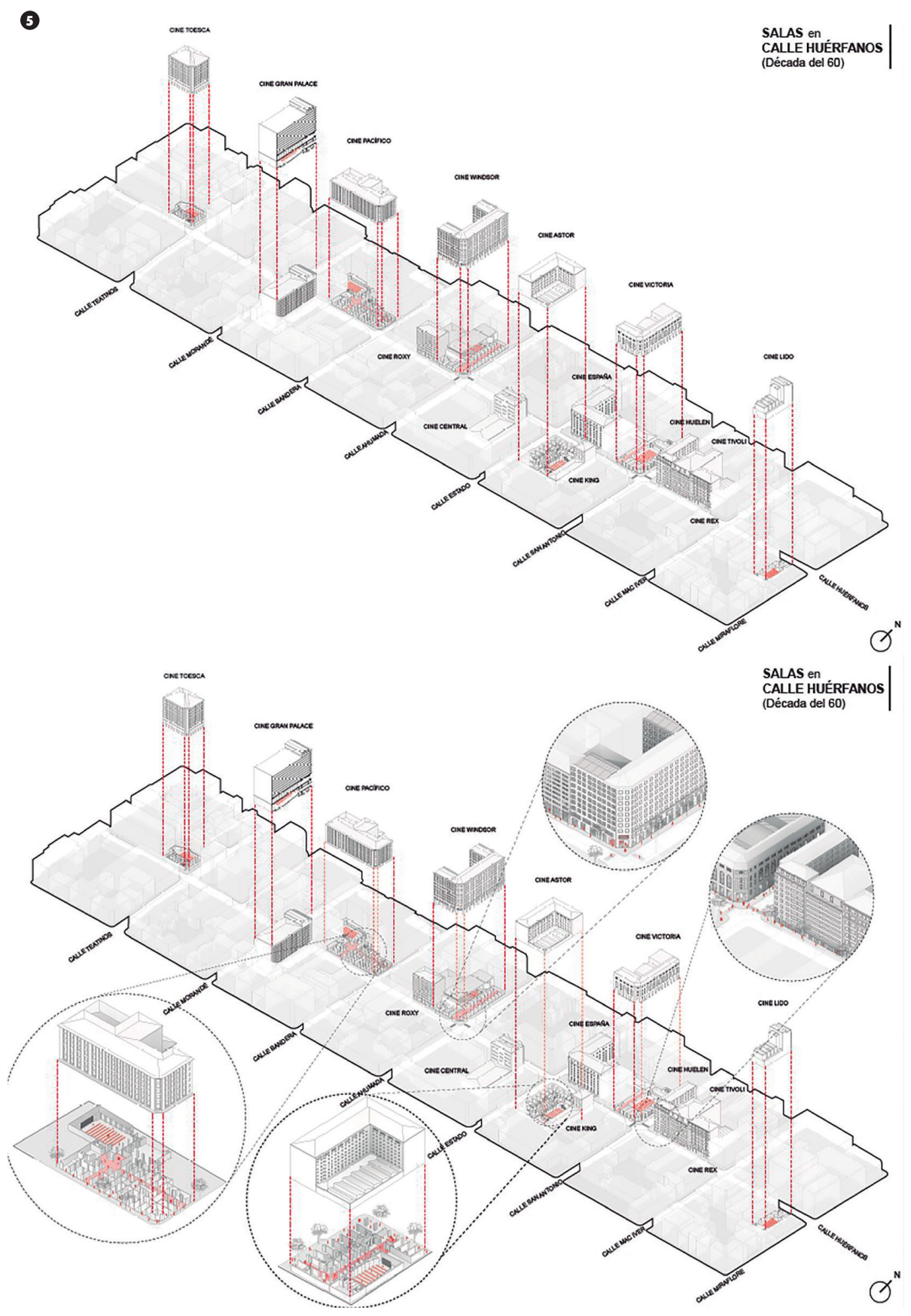


La materialidad constructiva y la decoración de los flamantes cines posibilitan al espectador acceder a un contexto extracotidiano, generando una experiencia que conjuga los aspectos propios de la entretención con la experiencia estética. En este contexto, el espectador, más allá de su condición social, accede a una experiencia democratizadora a partir de la experiencia sensible de una materialidad propia de la exhibición, que propone la sala de cine como dispositivo. De este modo el cine extiende la estética de los espacios de exhibición de las bellas artes ahora frente a un arte reciente concretado desde lo masivo.

La apertura de nuevos templos: Metro (en 1936) y Santa Lucía (1937), se ubican en calles que perfilaron los usos de suelo comercial e institucional (dependencias estatales, bancos, oficinas). Con posterioridad, la concentración de salas acabó conformando a Huérfanos como "la calle de los cines" (Figura 5). Esta calle tuvo su semejante en la ciudad de Buenos Aires: Lavalle ${ }^{[9]}$, que más allá de la cantidad de salas agrupadas, implicaba una cantidad inaudita de personas circulando (Labaqui, 2017, p. 128) lo que ocasionó, en ambos casos, que acabaran siendo peatonalizadas.

En la calle Huérfanos del centro santiaguino se desplegaron (FIGURA 6) tres tipos de salas:

- cine-palacio: King (1954) sala que tuvo una gran capacidad de butacas, y el tamaño de su fachada de triple altura servía como atractivo para atraer la audiencia.

- cine-galería: Victoria (1926) Astor (1950), Pacífico (1951), Windsor (1955), Huelén (1957), Roxy (1055), Tívoli (1963), Gran Palace (1963), España (1959), recintos de menor capacidad con relación a las grandes salas, ya que estos se integraban al paseo comercial público de las galerías, generalmente ocupando superficie en el
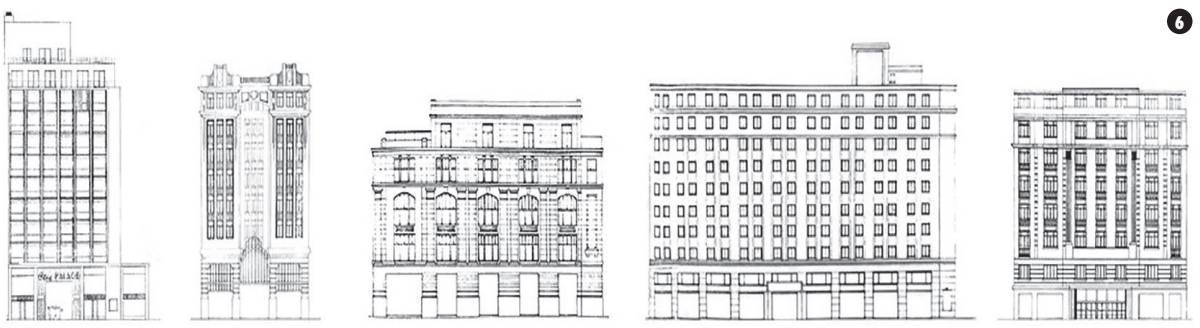

GRAN PALACE 1957
VICTORIA

1924
REX subterráneo. La marquesina se ubicaba en los accesos de dichos paseos con avisadores sobre la línea de vereda.

- cine con oficinas: Central (1933), Rex (1946), Toesca (1955), Lido (1957), salas de gran superficie y capacidad de público, que conformaban la contraparte de un bloque de oficinas. En las fachadas, la marquesina se complementaba más simplificada con el dominio de ventanas regulares, y por eso, los vestíbulos pierden la doble altura, preponderando la presencia de las unidades de renta a la calle.

La pujante actividad cinematográfica de la calle Huérfanos revela que, del inicial catálogo estilístico de fachadas que ofrecían los cines del centro, se reemplaza por un muestrario de títulos, en el cual los afiches -con diversas dimensiones- se tornaron nuevos protagonistas del paisaje urbano (FIGURA 7). En efecto, las fachadas relegan su protagonismo para convertirse en soporte de la exhibición. Allí fue donde se colocan llamativos letreros luminosos, atractivas carteleras y el despliegue de imágenes extraídas de los fotogramas, elementos que revela la evolución de elementos de una excepcional "arquitectura comercial nocturna" (Ávila, 2015, p. 56) que prolonga la concurrencia de ciudadanos en el centro santiaguino.

\section{CONSIDERACIONES FINALES}

En esencia, la sala de cine en Santiago demuestra que fue un programa de arquitectura levantado en concordancia con una planificación urbana renovadora y que logró detonar actividades complementarias, transformando el contexto funcional del centro santiaguino y los hábitos de sus ciudadanos.

La cronología de este artículo (1930-1960) expone que las salas homologan una estructura espacial para comercializar de igual modo la proyección de películas mientras que sus formas y cualidades estéticas varían. Todo este conjunto de obras forjan un territorio del gusto en el imaginario de la audiencia, y donde se considera a estos edificios puntos de referencia en el paisaje urbano y lugares de encuentro.

En la concentración de la llamada "calle de los cines" también se verifica que la tipología de sala cinematográfica es un paradigma, dado que contiene un discurso de la historia moderna de Santiago como ejemplo de la ciudad occidental del siglo XX. A su vez, revela una serie de exploración espacial, por cuanto los edificios pueden considerarse ensayos donde se adaptan a las constantes exigencias de la exhibición mientras se acomodan a los avances tecnológicos.

En esta secuencia presentada, las variantes de las salas de cine se evidencia especialmente en fachadas y vestíbulos, dos elementos que actúan como fuelle entre lo público y privado

9] En comparación, en solo 4 cuadras de la calle Lavalle se concentraban 17 salas. 
7. Vista nocturna de calle Huérfanos antes de convertirse en peatonal

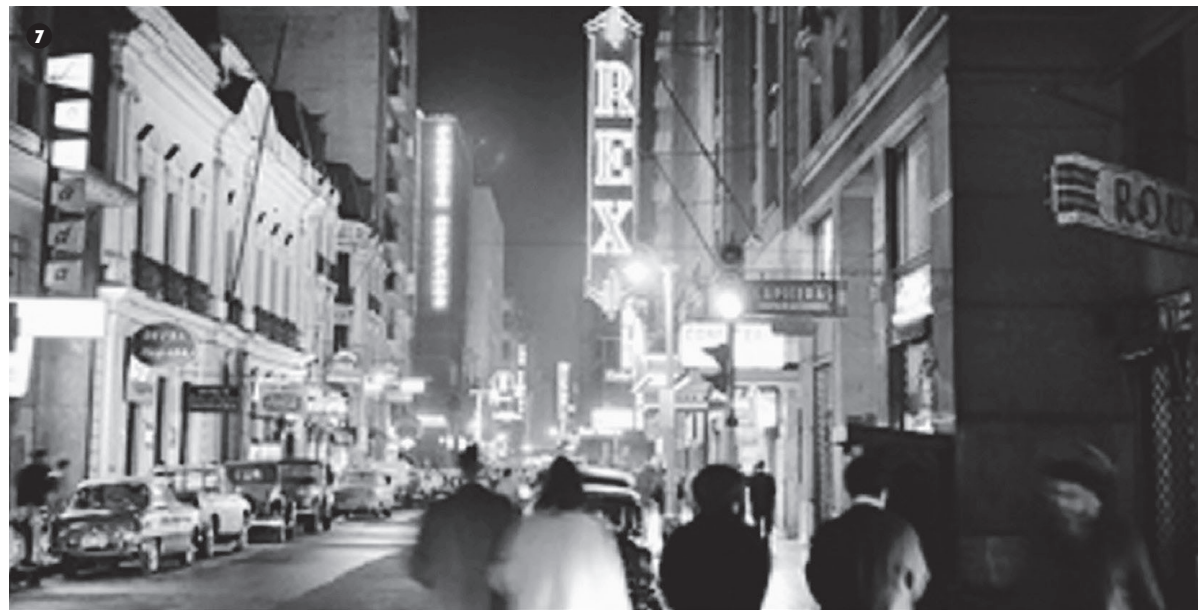

interior. Aun con cambios de dimensión, la única configuración constante que permanece es la sala, que hasta hoy, es donde se mantiene vigente la convocatoria de público, cumpliendo su función original: proyectar ilusiones en la oscuridad.

\section{BIBLIOGRAFÍA}

Alfaro, F. - Ochoa, A. (2019). Los palacios cinematográficos de la Ciudad de México. Apuntes: Revista de Estudios sobre Patrimonio Cultural, 32(1). https://doi.org/10.1 1144/ Javeriana.apc32-1.cpcc

Arizaga, X. (2019). Propuesta de caracterización de la renovación urbana en Chile. El caso de la comuna de Santiago Centro. EURE (Santiago) vol.45 no. 134 Santiago ene. 2019 http://dx.doi. org/10.4067/S0250-71612019000100169
Ávila, A., Montaño, A. (2015) Salas de cine en Bogotá (1897-1940): la arquitectura como símbolo de modernización del espacio urbano. Amérique Latine Histoire et Mémoire. Les Cahiers ALHIM [En línea], 29 | 2015. http:// journals.openedition. org/alhim/5230

Ávila, A. (2015). Las fachadas luminosas de las salas de cines. Revista Bitácora arquitectura (29) 48-57. http://dx.doi.org/10.22201/ fa. 14058901 p. 2015.29 .56256

Avilés, Rodrigo. 2012.92 cines. Los cines de Santiago. Santiago: Metales pesados.

Cozarinsky, E. (2006). Palacios plebeyos. Buenos Aires: Editorial Sudamericana.

Fuenzalida, O., Rosende, G. (1980) Arquitectura de los cines de Santiago. Investigación monográfica. Escuela de Arquitectura, Universidad de Chile.

García, M., Méndez, P. (2010). Cines de Buenos Aires. Patrimonio del siglo XX. Buenos Aires: Ediciones Cedodal.
Iturriaga, J. (2018). Salas de cine en Santiago de Chile: teatros, "barracones" y coliseos, 1896 1940. Apuntes, 31 (1), 24-37. https://doi. org/10.11144/Javeriana.apc31-1.scsc

Purcell, F. (2012). iDe película! Hollywood y su impacto en Chile 1910-1950. Santiago: Editorial Taurus.

Labaqui, F. (2017). Catedrales de la modernidad. Cines porteños 1896-1945. Buenos Aires: Comisión Nacional de Monumentos.

Lavilla-Iribarren, A. (2016). Evolución paralela del relato fílmico y la arquitectura de los cines entre 1900 y 1930. Atención especial al caso español. Revista de Arquitectura, 18 (2), 60-70. doi:10.14718/RevArq.2016.18.2.6

Martínez García, J. S. (2017) "El habitus. Una revisión analítica". Revista Internacional de Sociología 75(3). doi: http:// dx.doi.org/10.3989/ ris.2017.75.3.15.115

Revert, Jordi (2012) "Nuevos diálogos" Revista L'Atalante, enero-junio. Número 13. p. 77

Romero, J. L. (2010 [1976]) Latinoamérica. Las ideas y las ciudades. Buenos Aires: Siglo Veintiuno Ediciones.

Rosas J., Hidalgo R., Strabucchi W. y Cordano I. (2010) "Santiago 1910. Tramas del ocio", ARQ, n 74: 68-71. https://doi.org/10.4067/s071769962010000100013

Valentine, M. (1994) The show starts on the sidewalk: an architectural history of the movie theater, London, Yale University Press.

Vizcaíno, M. (2020). Cine-Esquina: un híbrido programático en la memoria de la ciudad chilena. Revista 180, 45, (14-23). http://dx.doi. org/10.32995/rev180.Num-45.(2020).art-746

Vyhmeister-Fábregas, K. (2019). La transformación de Santiago: un caso frustrado de intervención urbana a gran escala (1872-1929). EURE (Santiago), 45(134), 213-235. https://dx.doi. org/10.4067/S0250-71612019000100213 